\title{
Posttraining self-stimulation and memory: A study of some parameters
}

\author{
DANIEL COULOMBE and NORMAN WHITE \\ McGill University, Montreal, Quebec, Canada
}

\begin{abstract}
The effects of varying the amounts of tone preexposure (latent inhibition) and posttraining self-stimulation on retention of a tone-shock association, measured by determining the amount of tone-induced suppression of drinking, were studied. Increasing amounts of pretraining tone exposure decreased retention over all levels of self-stimulation, and increasing amounts of posttraining self-stimulation increased retention over all levels of preexposure. The interaction between these two factors suggests that they both acted on the strength of the tone-shock association. The preexposure acted proactively to weaken the association, and the self-stimulation acted retroactively to strengthen it. The effects of delaying the posttraining stimulation for various times after the tone-shock pairings was also investigated. Retention was improved by selfstimulation delayed for 15 or $30 \mathrm{~min}$, but was not affected by self-stimulation delayed for $1 \mathrm{~h}$. These experiments are interpreted as indicating that posttraining self-stimulation acts to improve retention by interacting with normally occurring processes of acquisition and retention.
\end{abstract}

Posttraining hypothalamic self-stimulation can improve the memory of rats in many different situations, including an instrumental water-finding task (Major \& White, 1978), aversive and appetitive classical conditioning situations (Coulombe \& White, 1980), and in a sensory preconditioning paradigm (Coulombe \& White, 1981). These findings have been interpreted as indications of a noncontingent, retroactive strengthening by self-stimulation of associations between the neural representations of various sensory events. These data are consistent with the work of a number of other investigators which suggests that the medial forebrain bundle and related structures are involved in mediating an effect of reinforcement on memory (Berman \& Kesner, 1976; Carder, 1970; Destrade \& Cardo, 1975; Destrade \& Jaffard, 1978; Fibiger \& Phillips, 1976; Huston, Mueller, \& Mondadori, 1977; Keesey \& Lindholm, 1969; Mondadori, Ornstein, Waser, \& Huston, 1976; Phillips \& Clouston, 1978; Routtenberg, 1975; Routtenberg \& Holzman, 1973).

Experimental paradigms designed to study improvements in retention produced by various posttraining treatments are often characterized by the fact that the subjects receive an amount of training that is by itself insufficient to produce a significant

Daniel Coulombe is now at the Department of Psychology, University of Ottawa. Requests for reprints should be sent to Norman White, Department of Psychology, McGill University, 1205 Dr. Penfield Avenue, Montreal, Quebec H3A 1B1, Canada. This research was supported by grants from the National Sciences and Engineering Research Council of Canada and from the FCAC program, Ministere d'Education, Province de Québec. We gratefully acknowledge the technical assistance of Mark Ferland, Michele Gadoury, and Kim Kovak. change in performance. Nevertheless, the assumption that this small amount of training produces some small amount of learning is necessary for these studies to be interpreted in terms of a retroactive improvement of retention by the posttraining treatment. As a test of this assumption, we attempted, in the present experiment, to vary the strength of the learning produced during training. It was hypothesized that the improvement in retention produced by posttraining self-stimulation would vary in a manner predictable from the different levels of initial learning produced during training.

To vary the strength of the initial learning, we used the phenomenon of latent inhibition, a paradigm in which nonreinforced preexposure to a to-be-conditioned stimulus produces a decrease in the effectiveness of that stimulus in subsequent conditioning (Carlton \& Vogel, 1967; Chacto \& Lubow, 1967; Holland \& Forbes, 1980; Leaf et al., 1968; Lubow \& Moore, 1959; Lubow \& Seibert, 1969). It has been reported that $10 \mathrm{CS}$ preexposures produce this effect (Lubow \& Moore, 1959) and that latent inhibition can affect both instrumental (Ackil \& Mellgren, 1968) and classical conditioning (see Siegel, 1972, and Lubow, 1973, for reviews). Reliable effects have been observed using a CER paradigm similar to the one used in the present experiment (Carlton \& Vogel, 1967; Leaf et al., 1968; Lubow, Schnur, \& Rifkin, 1976; Lubow \& Siebert, 1969).

A second parameter investigated in the present study was the effect on retention of varying the amount of posttraining reinforcement. In an experiment on the effect of varying the amount of posttraining self-stimulation, White and Major (1978) found that 30 trains of self-stimulation had no effect, 
but 1,000 trains improved retention of an instrumental water-finding task. However, in most of the research on posttraining facilitation of retention by brain stimulation (Berman \& Kesner, 1976; Destrade \& Cardo, 1975; Mondadori et al., 1976), the stimulation lasted for about $30 \mathrm{sec}$, which is roughly equivalent to the time it takes for a rat to get $\mathbf{3 0}$ trains of self-stimulation. Therefore, further investigation of this parameter is of some interest. It is well known that performance improves with increases in the amount of reinforcement, the relation being negatively accelerated (Crespi, 1942, 1944; Hutt, 1954; Logan, 1960; Zeaman, 1949). In the present case, it was hypothesized that retention would increase with increasing amounts of posttraining self-stimulation.

The third parameter investigated here was the time course of the retroactive effect of self-stimulation on memory. Earlier experiments showed that selfstimulation delayed for $1 \mathrm{~h}$ did not produce a facilitation of memory for a water-finding task (Major \& White, 1978), and that self-stimulation delayed for $2 \mathrm{~h}$ failed to produce an effect in two different classical conditioning tasks involving appetitive and aversive reinforcers (Coulombe $\&$ White, 1980). In a sensory preconditioning paradigm, a delay of $4 \mathrm{~h}$ was necessary to eliminate the effect of self-stimulation retention (Coulombe \& White, 1981). To study more precisely the time course of the retroactive effect of self-stimulation on the memory of associations formed in a classical conditioning situation, groups of animals received posttraining self-stimulation with various delays.

\section{GENERAL METHOD}

\section{Subjects}

Male hooded rats, weighing 275-325 $\mathrm{g}$ at the beginning of the experiment, were used. One hundred and thirteen of these animals underwent standard stereotaxic surgery under $50 \mathrm{mg} / \mathrm{kg}$ sodium pentobarbital anesthesia to implant an electrode aimed at the lateral part of the lateral hypothalamus (coordinates 4.4, 1.5, -2.1; de Groot, 1959). Approximately 7 days after surgery, these rats were trained to barpress for self-stimulation, and a stimulation intensity that yielded a constant rate of responding greater than 1,000 responses within 30 min was determined for each rat (range: $30-100 \mu \mathrm{A}, 60-\mathrm{Hz}$ sine wave, .5-sec trains). Ninety-four rats met this criterion and were assigned to various self-stimulation groups. Nineteen animals failed to reach the criterion after two training sessions. Five of these rats were used in the no selfstimulation groups together with 27 additional rats that did not undergo surgery.

\section{Apparatus}

The monopolar stimulating electrodes were made of stainless steel (.2-mm diameter), insulated with Formvar except for the cross section of the tip. An indifferent electrode was connected to the skull screws.

The training chamber $(20.5 \times 20.5 \times 25 \mathrm{~cm})$ was made of whitepainted Plexiglas, except for the front wall, which was clear Plexiglas. The floor was made of stainless steel rods connected to a Grason-Stadler shock generator set to deliver .6-mA shocks. A high-frequency response speaker was fixed to one of the opaque walls and was connected to an audio signal generator set to deliver a $12-\mathrm{kHz}$ tone at approximately $15 \mathrm{~dB}$ above background noise level. The chamber was illuminated by a $25-W$ light bulb, and was installed in a sound-attenuating enclosure.

The test chamber was identical to the training chamber, except that it was painted black. The grid floor was connected to a drinkometer circuit with a stainless steel drinking tube that protruded from a side wall. The drinking tube was covered by a Plexiglas shield so that only its tip could be contacted. The test chamber was located in a dark, sound-attenuating enclosure.

The self-stimulation cage $(20.5 \times 20.5 \times 40 \mathrm{~cm})$ was constructed of three wooden walls with a Plexiglas front. A Plexiglas bar (7.6 $\times 3.8 \mathrm{~cm}$ ) protruded from the center of a side wall of the cage, $3 \mathrm{~cm}$ from the floor.

\section{Procedure}

Water was removed from the animals' home cages $48 \mathrm{~h}$ before the training day. On the training day, each animal was placed into the black test chamber for $15 \mathrm{~min}$, during which water was freely available. During this period, each animal was preexposed to a series of 10-sec tones. After this habituation and tone preexposure period, the rats were returned to their home cages until the training session, 2 h later.

For the training session, each rat was placed into the white training chamber. In the paired condition, presentations of the 10-sec tone were paired with a $.5-\mathrm{sec}$ footshock that terminated at the same time as the tone. These tone-shock pairings were presented at 1-min intervals. In the unpaired condition, the tone was presented for $10 \mathrm{sec}$, followed $30 \mathrm{sec}$ later by a .5-sec footshock. These training trials occurred at 1-min intervals. Immediately after this training session, the rats were put into self-stimulation cages where they either were or were not allowed to barpress for lateral hypothalamic self-stimulation. Then the animals were returned to their home cages.

Twenty-four hours after its training session, each rat was placed into the black test chamber and allowed to drink freely until a period of $10 \mathrm{sec}$ had elapsed with no pauses longer than $2 \mathrm{sec}$ between consecutive licks. At the end of such a 10-sec period of continuous licking, the tone came on for $10 \mathrm{sec}$, and the full 20-sec period was defined as a trial. The next trial was initiated when a rat licked continuously for another $10 \mathrm{sec}$. Each rat was given eight trials. A suppression ratio was calculated for each block of two trials by dividing the number of drinkometer counts made when the tone was on by the total number of counts made during the two complete trials.

At the end of this procedure, the animals were killed with an overdose of chloral hydrate and perfused intracardially with physiological saline and $10 \%$ buffered Formalin. Frozen brain sections were cut at $40 \mu$ and stained with thionin for histological examination of brain stimulation sites.

\section{EXPERIMENT 1}

The purpose of this experiment was to demonstrate that latent inhibition could be observed in the conditioned suppression paradigm. To accomplish this, the number of preexposures to the tone was varied.

\section{Procedure}

Two groups of rats that had been preexposed to the tone $5(n=7)$ and $15(n=7)$ times, respectively, during the preexposure period received a training session consisting of 10 paired training trials. Two other groups of rats that had been preexposed to the tone 5 $(n=7)$ and $15(n=7)$ times, respectively, received two such training trials. No 0-preexposure group was included in this experiment, since earlier observations had indicated that the tone, when presented for the first time, had strong suppressive effects indepen- 


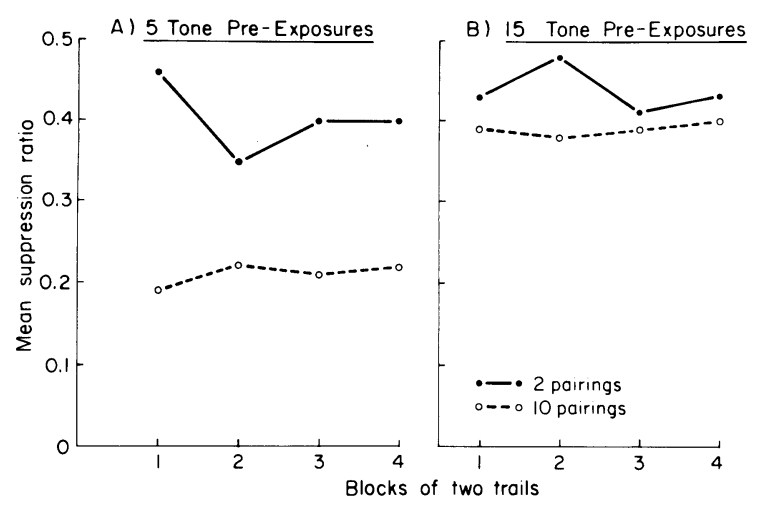

Figure 1. Mean suppression ratios for the rats in Experiment 1, as a function of number of preexposures to the tone and number of tone-shock pairings.

dent of the experimental conditions. Twenty-four hours after training, each of the rats was tested for conditioned suppression of drinking, as described in General Method.

\section{Results}

Figure 1 summarizes the retention test behavior of these animals. The suppression ratios were treated with an arc-sine transformation followed by a threeway ANOVA with repeated measurements over one factor (blocks of two trials). The arc-sine transformation was used because the possible heterogeneity of covariance needed to be dealt with and because the scores were proportions (Winer, 1971). The betweensubject factors were the amount of tone preexposure and the number of training trials.

There was a significant interaction between the number of preexposures and number of training trials factors $[F(1,24)=5.44, p<.05]$. As can be seen in Figure 1, this interaction was due to the fact that 10 pairings produced a significant suppression of drinking in the 5-preexposure condition, but failed to do so in the 15-preexposure condition. This finding shows that the procedure used in the present experiment produced the latent inhibition effects. That is, increasing the number of preexposures to the tone weakened the tone-shock association. The analysis of variance also revealed that the 10-pairing condition produced a significantly greater amount of suppression than did the 2-pairing condition $[F(1,24)=$ $12.44, \mathrm{p}<.01$ ]. Finally, 5 preexposures to the tone produced significantly more suppression of drinking than did 15 preexposures $[\mathrm{F}(1,24)=8.14, \mathrm{p}<.01]$.

\section{EXPERIMENT 2}

In Experiment 1, it was shown that latent inhibition could be observed in the conditioned suppressionof-drinking paradigm. The purpose of the present experiment was to investigate the effect of latent inhibition on the memory improvement effect induced by self-stimulation.

\section{Procedure}

There were eight groups of rats in this experiment, making up a $2 \times 4 \times 4$ factorial design, with two levels of tone preexposure ( 5 and 15), four levels of number of trains of self-stimulation (SS) (0, $30,480,1,000$ ), and four blocks of two trials (within factor). Each animal received two training trials. The 5-preexposure 0-SS group comprised five implanted rats that had failed to reach the selfstimulation criterion and 5 unimplanted rats. The 15-preexposure 0-SS group comprised seven unimplanted rats. These animals remained in the self-stimulation cages for $30 \mathrm{~min}$ after training but were not connected to the stimulator. The 5-preexposure 30-SS $(n=8)$, 480-SS $(n=11)$, and 1,000-SS $(n=11)$, and the 15-preexposure 30-SS $(n=8), 480$-SS $(n=8)$, and 1,000-SS $(n=9)$ groups all comprised animals that had met the self-stimulation criterion. They were placed into self-stimulation cages after training and allowed to barpress for the appropriate number of trains of self-stimulation.

\section{Results}

Examination of the histological material showed that most of the electrode tips were located within the area shown to produce a retroactive improvement in retention by Major and White (1978). However, all subjects that met the initial self-stimulation criterion, regardless of the precise location of their electrodes (see Figure 2), were included in the statistical analysis.

The retention test behavior of the rats in this experiment is summarized in Figure 3. These data were treated with an arc-sine transformation and subjected to a three-way analysis of variance with two levels of tone preexposure, four levels of amount of selfstimulation, and four levels of trial blocks (repeated measures). In order to deal with unequal Ns, the unweighted means solution was used (Winer, 1971). As shown in Figure 3, the 5-tone-preexposures groups had lower suppression ratios than the 15-tone-preexposures groups. The analysis of variance showed that this preexposure effect was statistically significant $[F(1,65)=9.23, p<.01]$, confirming the latent inhibition effect. Figure 3 also shows that the higher the number of self-stimulations, the lower the suppression ratios, a trend which was statistically confirmed by a significant main effect of self-stimulation $[F(3,65)=3.55, p<.05]$. There was a significant interaction between the self-stimulation and preexposure factors $[F(3,65)=2.78, p<.05]$, and this interaction was mainly due to the fact that 1,000 SS had a larger effect at 5 preexposures than it did at 15 preexposures $[F(1,65)=16.87, p<.01]$. This interaction indicates that preexposures and self-stimulation had simultaneous and reciprocal effects on the suppression ratios. Increasing the number of preexposures increased the suppression ratios over all levels of self-stimulation, suggesting that retention of the tone-shock association was impaired. Increasing the amount of self-stimulation, on the other hand, decreased the ratios at both levels of preexposure, suggesting that retention was improved.

There was also a significant trial block effect $[F(3,195)=7.72, p<.01]$, indicating that extinction 


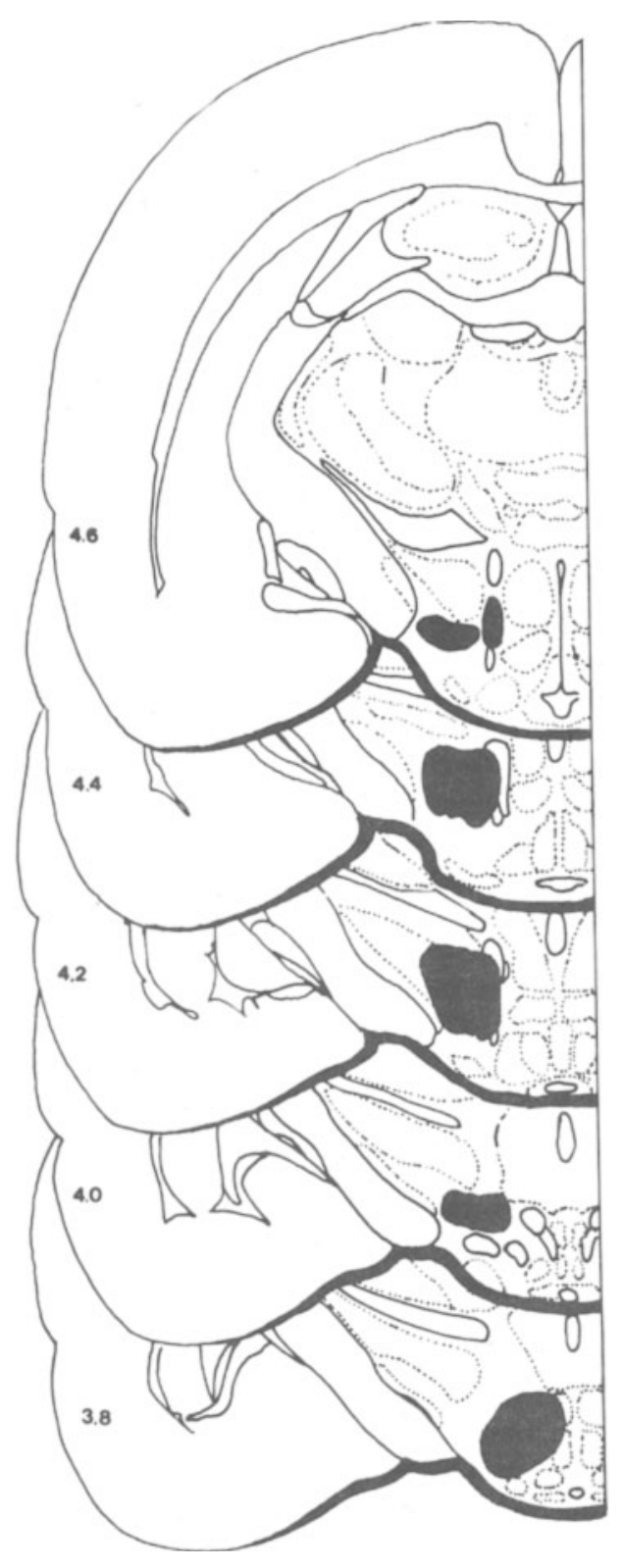

Figure 2. Brain sections showing area (in black) that included the tips of the electrodes of the 94 self-stimulating rats.

occurred over the eight unreinforced test trials. The trial block factor was different for the two levels of preexposure $[\mathrm{F}(3,195)=3.64, \mathrm{p}<.05]$ and, as is apparent from Figure 3, this result was due to the relatively small amount of suppression at 15 preexposures. The analysis of simple effects was significant for the first two trial blocks at 5 preexposures $[F s(1,195)=15.33$ and 7.93 for Blocks 1 and 2, respectively; ps $<.011$.

The trial block $x$ self-stimulation interaction was also significant $[F(9,195)=2.07, p<.05]$, which suggests, with reference to Figure 3, differing rates of extinction for rats that received different amounts of self- stimulation. Tests of simple effects showed that the effect of self-stimulation was significant for the first two trial blocks $[F s(3,195)=10.69$ and 4.40 for Blocks 1 and 2, respectively; ps $<.01$ ]. On the first trial block, post hoc LSD tests (Winer, 1971) showed that there was significantly more suppression of licking at all self-stimulation levels than at no selfstimulation (0 SS) $(p<.05)$. There was no significant difference between the 30-SS and the 480-SS groups, and both of these groups showed less suppression of licking than the 1,000-SS group ( $p<.05)$. On the second trial block, post hoc LSD tests showed no significant difference between the 30-SS and the 0SS groups. The increased suppression of licking in the 480-SS and the 1,000-SS groups, as compared with the 0 -SS group, was maintained $(p<.05)$ on the second trial block.

An analysis of variance comparing the suppression ratios of the implanted and the unimplanted subjects in the 5-tone-preexposures 0-SS group showed no significant difference $[F(1,9)=.486]$. This result shows that the surgical procedure alone did not significantly affect the performance of the animals.

Two additional checks on the validity of the data in this experiment were made. First, as shown in Figure 3, an additional group of rats was run using the unpaired training procedure described in General Method (5 tone preexposures, 1,000 trains of self-stimulation). An analysis of variance comparing the suppression ratios for this group with those for the group with the same parameters trained with the paired procedure was significant $[F(1,18)=6.97$, $\mathrm{p}<.05]$. This finding shows that the effect of selfstimulation depended upon the association of the tone and the shock, and that it was not the result of tone-stimulation or shock-stimulation associations or of proactive effects of the stimulation upon retention test performance. The second check was a $2 \times 4 \times 4$ analysis of variance on the number of .5-sec periods the rats spent licking during the pretone periods on the retention tests. None of the interac-

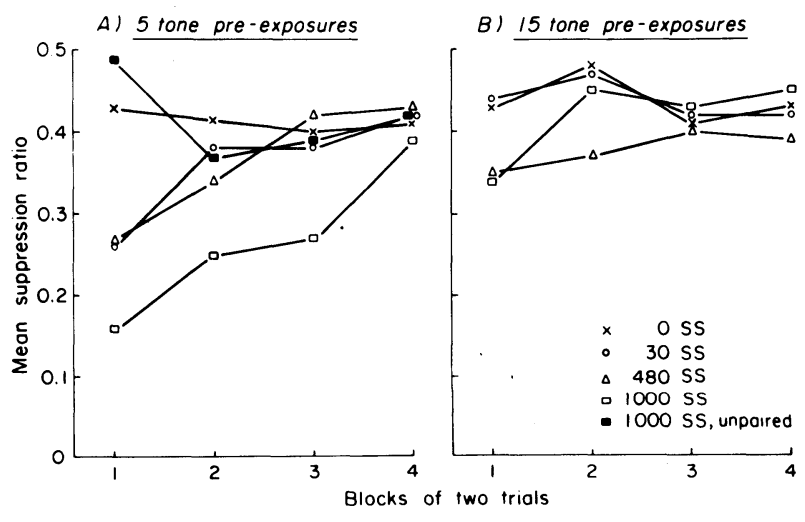

Figure 3. Mean suppression ratios as a function of preexposure to the tone, self-stimulation, and trial block factors. 
tions in this analysis was significant, and the only significant main effect was blocks of trials $[F(3,195)$ $=7.828, \mathrm{p}<.0001]$. Thus, there is no way to account for the differences among the groups on the basis of differences in the amount of pretone responding. The means of the total number of periods of licking during the four blocks of trials, summed over all conditions of the experiment were: $37.5,37.8,35.9,35.9$. This pattern of differences could have contributed a small part of the trial-by-trial extinction effect observed between Blocks 2 and 3.

\section{EXPERIMENT 3}

This final experiment was designed to examine the time course of the effect of lateral hypothalamic selfstimulation on retention by imposing various delays between the training period and the posttraining treatments.

\section{Method}

Subjects. Thirty male hooded rats, weighing approximately $300 \mathrm{~g}$ at the start of the experiment, were used as subjects. All the animals were implanted with monopolar electrodes aimed at the lateral hypothalamus. The data obtained in the previous experiment for two groups of subjects were included in the analysis (no self-stimulation groups and immediate self-stimulation).

Procedure. Each animal received five tone preexposures, and two tone-shock pairings during training. The rats in one group $(n=10)$ did not self-stimulate after training. The rats in a second group $(n=8)$ were placed into self-stimulation cages immediately after training. The rats in the three remaining groups were returned to their home cages and placed into self-stimulation cages after three different posttraining delays: $15 \mathrm{~min}(n=10), 30 \mathrm{~min}$ $(n=9)$, and $60 \mathrm{~min}(n=11)$. Each rat was allowed to barpress for 30 trains of self-stimulation. Twenty-four hours later, each animal was tested for conditioned suppression.

\section{Results}

The histological material for the rats in this experiment showed that the electrode tips were distributed similarly to those of Experiment 2 (see Figure 2). The behavioral results for the delay variable are summarized in Figure 4. These data indicate that delays of $30 \mathrm{~min}$ or less between the training and the selfstimulation produced similar amounts of suppression. However, the function increased as the delays increased from 15 to $60 \mathrm{~min}$. The one-way ANOVA revealed a significant treatment effect $[F(4,44)=4.42$, $\mathrm{p}<.01]$ and post hoc LSD tests showed that immediate self-stimulation and stimulation delayed by either 15 or 30 min produced a decrease in suppression of licking as compared with the NSS group $(p<.05)$. On the other hand, self-stimulation delayed by $1 \mathrm{~h}$ had no effect as compared with the NSS group.

\section{DISCUSSION}

The results of the present experiments show that the effect of posttraining self-stimulation varies when

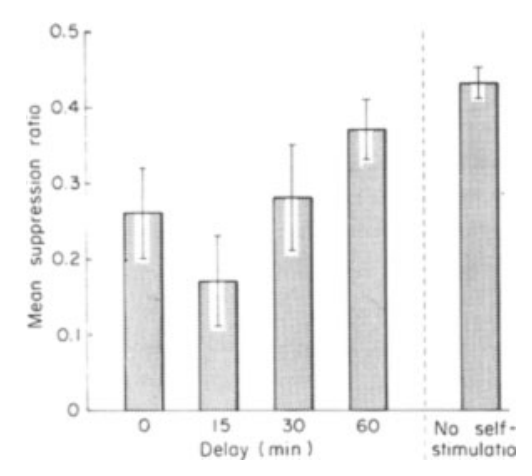

Figure 4. Mean suppression ratios on the first trial block as a function of various delays between training and posttraining self-stimulation. The vertical lines on each bar represent standard errors.

the strength of the CS-UCS association is manipulated by varying the number of CS preexposures. When the association could have been assumed to be strong ( 5 tone preexposures), the effect of the selfstimulation treatment was similar to that observed previously (Coulombe \& White, 1980). However, when the association could have been assumed to be weak (15 tone preexposures), only very small effects of self-stimulation could be detected. It was also shown that increasing the amount of posttraining self-stimulation affected retention scores in an increasing fashion, since 1,000 self-stimulations produced better retention scores than did $\mathbf{4 8 0}$ or $\mathbf{3 0}$ self-stimulations. Finally, the data showed that the effect of self-stimulation decreased with increases in the delay between the training trials and the posttraining treatment.

Varying the number of preexposures to the tone prior to training indicated that 15 preexposures increased the suppression ratios. These data were predictable from the work of others who studied the phenomenon of latent inhibition and observed a decremental effect of CS-preexposures on subsequent conditioning (Carlton \& Vogel, 1967; Leaf et al., 1968; Lubow, 1965; Lubow \& Morre, 1959; Lubow, Schnur, \& Rifkin, 1976; Lubow \& Siebert, 1969; Siegel, 1972). Although it remains unclear whether this effect is due to the elimination of the orienting response, which is thought to be important in the process of conditioning (Matzman \& Raskin, 1965), to a reduced stimulus salience (Rescorla, 1971), to the association of a response antagonistic to the conditioned response with the CS during the preexposures (Lubow \& Moore, 1959; Siegel, 1972), or to any other mechanism (Lubow, 1973), it seems reasonable to postulate that preexposures to the CS can effect the CS-UCS associative strength in subsequent conditioning situations. As there was only a slight effect on retention in any of the 15-preexposure groups, it is concluded that in these animals the tone-shock associations were to weak to be affected 
by the self-stimulation. On the other hand, five tone preexposures allowed the formation of an association of sufficient strength to be affected by the SS.

The data concerning the effect of varying the amount of posttraining self-stimulation indicated that an effect on memory can be observed at all levels of self-stimulation tested, but that with lower levels of this treatment (30 SS and 480 SS), the suppression produced by the tone extinguished faster. This finding is predicted by the hypothesis that the selfstimulation acted retroactively to strengthen the CSUCS association: the amount of strengthening was directly proportional to the amount of stimulation.

The fact that 30 trains of self-stimulation produced an effect in the present experiment appears inconsistent with results reported previously (Major \& White, 1978), which indicated that 1,000 SS produced an effect on the retention of an instrumental water-finding task, but that 30 SS did not do so. These contradictory results could be due to a number of differences in the two experiments. However, it seems likely that, in the present experiment, the strength of the initial association at five preexposures was sufficiently strong for even low levels of self-stimulation to strengthen it, while the corresponding association formed in the water-finding task was initially weaker, so that only high levels of self-stimulation could improve its retention.

The fact that reduced amounts of self-stimulation produced an effect on memory in the present experiment also allows some degree of comparison with the results obtained by other researchers who used short sessions of experimenter-administered hypothalamic stimulation to influence retention. For example, Huston, Mueller, and Mondadori (1977) gave rats $30 \mathrm{sec}$ of hypothalamic stimulation $(.2 \mathrm{sec}$ off and $.8 \mathrm{sec}$ on) after an avoidance task, and observed a facilitation of retention. In the present experiment, the time spent by the rats to get 30 trains of selfstimulation was roughly $30 \mathrm{sec}$, so the amounts of brain stimulation and the results of the two experiments are comparable. However, White and Major (1978) also reported that 30 trains of experimenteradministered stimulation (as opposed to 30 trains of self-stimulation) facilitated retention of the waterfinding task. They suggested that some factor beyond the simple activation of a particular set of neurons by the stimulation was important for observing the facilitation of retention. Since a facilitation was observed following 30 trains of self-stimulation in the present study, it seems likely that there is an interaction between the nature of the learning task studied (possibly including the strength of the association produced by the procedure) and the amounts and type of posttraining treatment.

The results of imposing a delay between the training and the self-stimulation treatment showed that self-stimulation at all delays tested up to $30 \mathrm{~min}$ produced more suppression than 0 SS. There was no increase in suppression in the group for which selfstimulation was delayed by $1 \mathrm{~h}$. This result indicates that 30 trains of self-stimulation is effective for less than $1 \mathrm{~h}$ after training. Although this estimate of 30$60 \mathrm{~min}$ is consistent with other research on the effect of various posttraining treatments that disrupt memory (Chorover, 1976; Dawson \& McGaugh, 1973; McGaugh \& Gold, 1976), the implications of this finding for estimates of the "consolidation time" are limited. Based on our finding that the effectiveness of the posttraining treatment is a function of the number of trains of self-stimulation, it seems likely that longer sessions of self-stimulation would be effective over longer posttraining delays.

\section{REFERENCES}

Ackil, J. E., \& Mellgren, R. L. Stimulus pre-exposure and instrumental learning. Psychonomic Science, 1968, 11, 339.

Berman, R. F., \& Kesner, R. P. Post-trial hippocampal, amygdaloid and lateral hypothalamic electrical stimulation: Effects on short- and long-term memory of an appetitive experience. Journal of Comparative Physiological Psychology, 1976, 90, 260-267.

CARder, B. Lateral hypothalamic stimulation and avoidance in rats. Journal of Comparative and Physiological Psychology, 1970, 71, 325-333.

Carlton, P. L., \& Vogel, J. R. Habituation and conditioning. Journal of Comparative and Physiological Psychology, 1967, 63, 348-351.

Chacto, C., \& Lubow, R. E. Classical conditioning and latent inhibition in the white rat. Psychonomic Science, 1967, 9, 135-136.

Chorover, S. An experimental critique of the "consolidation studies" and an alternative "model-systems" approach to the biophysiology of memory. In M. R. Rosenzweig \& E. L. Bennett (Eds.), Neural mechanisms of learning and memory. Cambridge: M.I.T. Press, 1976.

Coulombe, D., \& White, N. The effect of post-training lateral hypothalamic self-stimulation on aversive and appetitive classical conditioning. Physiology \& Behavior, 1980, 25, 267-272.

Coulombe, D., \& White, N. The effect of post-training hypothalamic self-stimulation on sensory preconditioning in rats. Canadian Journal of Psychology, 1982, 36, 57-66.

Crespi, L. P. Quantitative variation of incentive and performance in the white rat. American Journal of Psychology, 1942, 55, 467-517.

Crespi, L. P. Amount of reinforcement and level of performance. Psychological Reviews, 1944, 51, 341-357.

Dawson, R. G., \& McGaugh, J. L. Drug facilitation of learning and memory. In J. A. Deutsch (Ed.), The physiological basis of memory. New York: Academic Press, 1973.

DE Groot, J. The rat hypothalamus in stereotaxic coordinates. Journal of Comparative Neurology, 1959, 113, 389-400.

Destrade, C., \& Cardo, B. Amelioration de la reminiscence par stimulation post-essai de l'hypothalamus lateral chez la souris BALB/C. Comptes Rendus de l'Academie des Sciences (Paris), 1975, 280 (D), 1401-1404. 
Destrade, C., \& Jaffard, R. Posttrial hippocampal and lateral hypothalamic electrical stimulations: Facilitation of long-term memory of appetitive and avoidance learning tasks. Behavioral Biology, 1978, 22, 354-374.

Fibiger, H. C., \& Phillips, A. G. Retrograde amnesia after electrical stimulation of the substantia nigra: Mediation by the dopaminergic nigro-neostriatal bundle. Brain Research, 1976, 116, 22-33.

Holland, P. C., \& Forbes, D. T. Effects of compound or element pre-exposure on compound flavor aversion conditioning. Animal Learning \& Behavior, 1980, 8, 199-203.

Huston, J. P., Mueller, C. C., \& Mondadori, C. Memory facilitation by posttrial hypothalamic stimulation and other reinforcers: A central theory of reinforcement. Biobehavioral Reviews, 1977, 1, 143-150.

HutT, P. J. Rate of bar pressing as a function of quality and quantity of food reward. Journal of Comparative and Physiological Psychology, 1954, 47, 235-239.

Keesey, R. D., \& Lindholm, E. P. Differential rates of discrimination learning reinforced by medial versus lateral hypothalamic stimulation. Journal of Comparative and Physiological Psychology, 1969, 68, 544-551.

Leaf, R. C., Kayser, R. J., Andrews, J. S., Adkins, J. W., \& LEAF, S. R. P. Block of fear conditioning induced by habituation or extinction. Psychonomic Science, 1968, 10, 189-190.

Log AN, F. A. Incentive. New Haven: Yale University Press, 1960.

LuBow, R. E. Latent inhibition: Effects of frequency of nonreinforced pre-exposure to the CS. Journal of Comparative and Physiological Psychology, 1965, 60, 454-455.

Lubow, R. E. Latent inhibition. Psychological Bulletin, 1973, 79, 398-407.

LuBow, R. E., \& Moore, A. U. Latent inhibition: The effect of nonreinforced pre-exposure to the conditional stimulus. Journal of Comparative and Physiological Psychology, 1959, 52, 416-419.

Lubow, R. E., Schnur, P., \& Rifkin, B. Latent inhibition and conditioned attention theory. Journal of Experimental Psychology: Animal Behavior Processes, 1976, 2, 163-174.

Lubow, R. E., \& Siebert, L. Latent inhibition within the CER paradigm. Journal of Comparative and Physiological Psychology, 1969, 68, 136-138.

MAJOR, R., \& WhITE, N. Memory facilitation by self-stimulation reinforcement mediated by the nigro-neostriatal bundle. Physiology \& Behavior, 1978, 20, 723-733.

Maltzman, I., \& Raskin, D. C. Effects of individual differences in the orienting reflexes on conditioning and complex processes. Journal of Experimental Research in Personality, 1965, 1, 1-16.

McGaugh, J. L., \& Gold, P. E. Modulation of memory by electrical stimulation of the brain. In M. R. Rosenzweig \& E. L. Bennett (Eds.), Neural mechanism of learning and memory. Cambridge, Mass: M.I.T. Press, 1976.

Mondadori, C., Ornstein, K., Waser, P. G., \& Huston, J. P. Post-trial reinforcing hypothalamic stimulation can facilitate avoidance learning. Neuroscience Letters, 1976, 2, 183-187.

Phillips, A. G., \& Clouston, R. Disruption of one-trial appetitive learning and passive avoidance following stimulation of the substantia nigra pars compacta. Behavioral Biology, 1978, 23, 388-394.

Rescorla, R. A. Summation and retardation tests of latent inhibition. Journal of Comparative and Physiological Psychology, 1971, 75, 77-81.

ROUTTENBERG, A. Intracranial self-stimulation pathways as substrate for memory consolidation. In M. R. Jones (Ed.), Nebraska Symposium on Motivation. Lincoln: University of Nebraska Press, 1975.

Routtenberg, A., \& Holzman, N. Memory disruption by electrical stimulation of the substantia nigra, pars compacta. Science, 1973, 181, 83-86.

Siegel, S. Latent inhibition and eyelid conditioning. In A. $\mathbf{H}$. Black \& W. F. Prokasy (Eds.), Classical conditioning II: Current research and theory. New York: Appleton-Century-Crofts, 1972.

Winer, B. J. Statistical principles in experimental design. New York: McGraw-Hill, 1971.

White, N., \& MajoR, R. Facilitation of retention by selfstimulation and by experimenter-administered stimulation. Canadian Journal of Psychology, 1978, 32, 116-123.

ZEAMAN, D. Response latency as a function of the amount of reinforcement. Journal of Experimental Psychology, 1949, 39, 466-483.

(Manuscript received August 20, 1981; revision accepted for publication July 14,1982 .) 